\title{
XXXIV. Unrecognized factors in the transmission of gases through water
}

\section{W.E. Adeney D.Sc.}

To cite this article: W.E. Adeney D.Sc. (1905) XXXIV. Unrecognized factors in the transmission of gases through water, Philosophical Magazine Series 6, 9:51, 360-369, DOI: 10.1080/14786440509463287

To link to this article: http://dx.doi.org/10.1080/14786440509463287

曲 Published online: 15 Apr 2009.

Submit your article to this journal

Џ Article views: 2

Q View related articles $\sqsubset$ 
illustrated by the formulæ given by M. Andresen*, and similar to the formula above (a), viz., for the spectral fraction between the lines $F$ and $G$ blackening silver-chloride paper,

$$
\mathrm{W}=4715 \times 10^{-\frac{0298 \mathrm{P}}{\operatorname{ens} \phi}} \text {. }
$$

The sunrays passed through a solution of auramine-O, that is, the spectral fraction situated about the line $D$, produce an effect on a silver-bromide paper that is sensitized with rhodamine-B, expressed by the formula

$$
W=1663 \times 10^{-\frac{0 \cdot 109 \mathrm{P}}{\cos \emptyset}}
$$

and the effect of the red rays, which are sitmated on the other side of $\alpha \frac{2}{5} \mathrm{D}$ (wave-length $610 \mathrm{j}$ is measured by a silver-bromide paper sensitized with a solution of chlorophyll, and is expressed by

$$
\mathrm{W}=445 \times 10^{-\frac{0 \cdot 117 \mathrm{P}}{\cos \bar{\phi}}} .
$$

These formula may also be expanded in a series of increasing powers of $\cos \phi$, and will then give expressions similar to the formula $(b)$, which may be integrated with regard to $t$. Those curves giving the distribution of the directly shining sunlight of the less refrangible spectral regions will be of the same nature as the one we have found for the more refrangible light, but they will not be equidistant, and their special points w ill probably not all correspond to the same latitudes.

Chemical Laboratory,

Royal Norwegian Agricultural College, Aas, near Kristiania.

XXXIV. Unrecognized Factors in the Transmission of Guses: through Water. By W. E. Aleney, D.Sc., Curator and Examiner in Chemistry in the Royal University, Dullin $\uparrow$.

THE question of the possibility of atmospheric gases being transmitted through water by any process other than that of diffusion, or by thermal currents, or mixing, does not appear to have been considered.

Hüfner $\$$ found, in his work on the diffusion coefficients of gases in water, that, if a gas be placed above the liquid, the phenomenon of diffusion is disturbed by downward

* Eder's Jahrbuch fuir Photographie etc. xiii. 1899, p. 149.

† Communicated by the Author. (Reprinted from Trans. Roy. Dubl. Soc. : read Dec. 20, 1904.)

† Ann. Phys. Chem. (11) vol. 1x. pp. 134-168 (1897). 
streaming effects through the water. He explains these as being caused by the water becoming heavier as it dissolves the gas, and sinking to the bottom.

Hüfner, in order to avoid this streaming effect, employed a thin plate of the porous mineral hydrophane to hold up a colunn of water in an experimental tube, and so provided the means of introducing the gas at the bottom of the water and of studying the upward diffusion of the gas.

The author has met with this downward streaming in the course of some experiments recently made upon the solution of atmospheric gases by water. It did not, however, appear to him that the cause of the streaming, as suggested by Hüfner, offered a wholly satisfictory explanation of the phenomenon observed. $\mathrm{He}$ accordingly thought that a careful investigation of this streaming effect might be followed by results of some value.

\section{Method of Experiment.}

Glass tubes about 2 metres long and 18 millims. bore have been employed for all the experiments to be described, except for a few preliminary ones. The dimensions of these will be given with the descriptions of the experiments.

The tubes were nearly filled either with distilled water or with sea-water, and warmed and exbausted as far as desirable by means of a mercury-pump. The corks closing the lower ends of the tubes were fitted with fine glass tubes to provide the means of attachment to the mercury-pump for exhaustion, and for drawing off samples.

After the gases in solution and in the air-spaces had been abstracted, the corks closing the upper ends of the tubes were removed, and the tubes for most of the experiments were immersed to a depth of about $1300 \mathrm{~mm}$. in a large waterjacket, which was kept cool by a constant flow through it of water from the main supply.

The object of the water-jacket was to prevent the formation of downward convection-currents, by keeping the lower portions of the water-columns in the tubes at a slightly lower temperature than the upper portions, which wore exposed to the temperature of the laboratory.

In most of the experiments to be described, the surfaces of the water-columns were kept constantly agitated by means of currents of air drawn through their upper layers. For the few preliminary experiments to be described, the tubes were fitted with corks carrying fine glass inlet and exit tubes of $3 \mathrm{~mm}$. bore, and for the later experiments with glass capillary tubes of $0.5 \mathrm{~mm}$. bore. The inlet-tubes have 
dipped at different depths, from 10 to $200 \mathrm{~mm}$., below the surface.

Slow currents of air were employed, at the rate of 1000 c.c. per hour, with the smaller bore inlet-tubes, and at somewhat quicker rates with the tubes of the larger bore.

In a few cases, the surfaces of the water-columns were agitated by mechanically rotated glass stirrers, just dipping below the surface of the water. In these cases the experimental tube employed was of wider bore to allow of stirrers of a gridiron shape being used.

When the surfaces of the water-columns were left unbroken, the experimental tubes were loosely covered to protect their contents from dust.

The height of the columns of water were in nearly all experiments about $1800 \mathrm{~mm}$. In all experiments the surfaces of the water were freely exposed to the air. Observations of baronetric pressures have not been thought necessary.

At the conclusion of each experiment, layers of the water of 100 to $200 \mathrm{~mm}$. thick were drawn from different depths from the surface, and stored in tubes standing over mercury until they could be analysed.

The dissolved gases in these samples were extracted by boiling with a little sulphuric acid in vacuo. The apparatus employed for this purpose, and for the analysis of the gases, has already been described by the author in his memoir on Dissolved Gases and Fermentative Changes*.

Of the results of the analysis of the dissolved gases, only those for the nitrogen are recorded in this communication. These are expressed in c.c. at $0^{\circ} \mathrm{C}$. and $760 \mathrm{~mm}$. bar. per litre.

\section{Dengriftion and Results of Experiments.}

\section{Experiments with Unbroken Surfaces.}

No. 1.-Two tubes, each $1950 \mathrm{~mm}$. long and $18 \mathrm{~mm}$. bore, were filled to the height of $1800 \mathrm{~mm}$. from the bottom, one with sea-water and one with distilled water, both being nearly nitrogen free, and were immersed in the waterjacket and kept undisturbed for 28 days. The temperature of the room varied between $16^{\circ} .5$ and $10^{\circ} \mathrm{C}$., that of the jacket between $12^{\circ} .9$ and $8^{\circ} .0 \mathrm{C}$. During the last week of the experiment the temperature of the room varied between $12^{\circ}$ and $10^{\circ}$ and that of the jacket between $9^{\circ}$ and $8^{\circ} \mathrm{C}$.

* Trans. Royal IJublin Society, vol, v. Part 2 (1895). 
Distilled water saturated at $10^{\circ} \mathrm{C}$. contains $15 \cdot 37$ c.c. $\mathrm{N}_{2}$ per litre. Sea-water saturated at $10^{\circ} \mathrm{C}$. contains $12 \cdot 47$ c.c. $\mathrm{N}_{2}$ per litre.

\begin{tabular}{|c|c|c|c|c|}
\hline $\begin{array}{l}\text { Depth of Layer } \\
\text { below surface. }\end{array}$ & & & a-water. & Distilled water. \\
\hline 1 to 200 & $\mathrm{~mm}$. & & $9 \cdot 24$ & 11.50 \\
\hline 300 to 500 & , & & $8 \cdot 96$ & $11 \cdot 10$ \\
\hline 800 to 1000 & , & & $8 \cdot 91$ & $8 \cdot 43$ \\
\hline 1600 to 1800 & ," & & $7 \cdot 89$ & $5 \cdot 84$ \\
\hline Before ačratio & & & 1.51 & 1.55 \\
\hline
\end{tabular}

No. 2.-Similar to No. 1 with the exception that the tubes were kept longer in the water-jacket, viz. for $2 \frac{1}{2}$ months. Temperature of room at close of experiment $17^{\circ} .8 \mathrm{C}$, of water-jacket $15^{\circ} \cdot 6 \mathrm{C}$.

Distilled water, at $17^{\circ} .8 \mathrm{C}$. contains $13{ }^{\prime} 29$ c.c. $\mathrm{N}_{2}$ per litre. Sea-water at $17^{\circ} .8$ C. contains 10.80 c.c. $\mathrm{N}_{2}$ per litre.

\begin{tabular}{|c|c|c|}
\hline $\begin{array}{l}\text { Depth of Layer } \\
\text { below surface. }\end{array}$ & Seq-water. & Distilled water. \\
\hline 1 to $200 \mathrm{~mm}$ & $.10 \cdot 80$ & $12 \cdot 56$ \\
\hline 1600 to 1800 & $10 \cdot 72$ & $9 \cdot 09$ \\
\hline
\end{tabular}

The foregoing results reveal a number of points of interest in connexion with the streaming effect above referred to.

The most noticeable is the marked difference in rate in sea- and distilled water, being much greater in the former than in the latter. Another point of interest is that the surface-layers of the sea- and distilled water, in No. 1, even after exposure to the air for 28 days, did not become saturated with nitrogen. Hence we may conclude that the streaming effect is more rapid in both sea- and distilled water than the rate of solution at the surface exposed to the air.

These experiments, so far as they go, may be regarded as supporting the suggestion of Hiilner, that the streaming is a gravitational effect due to concentrated solution currents. The following experiment, however, affords conclusive evidence that the streaming is really a gravitational effect.

No. 3.-A U-shaped tube, each limb $1600 \mathrm{~mm}$. long and $50 \mathrm{~mm}$. diameter, was filled with boiling sea-water and immediately closed air-tight with indiarubber corks. When the water bad cooled, the tube was further exhausted by means of a mercury-pump. One limb was then uncorked, and the water in it was saturated with atmospheric gases by a current of air drawn through the 
surface-layer to a depth of $50 \mathrm{~mm}$. for 48 loonrs. After this, a sample was drawn from the bottom of the open limb, and one from the lower portion of the closed limb, about $200 \mathrm{~mm}$. from the bottom. The gases were extracted from these and the nitrogen in exch determined, witl the following results :-

Open Limb.

$12 \cdot 12$

Closed Limb. $1 \cdot 49$

Six months later another sample was collected from the lower portion of the elosed limb, as before, and the nitrogen in it determined; it was $1 \cdot 73$

\section{Experiments with Broken Surfaces.}

The experiment No.1, and several others which were made during the earlier part of this investigation, but which it is unnecessary here to record, since the results were similar, shows that a retardation of solution takes place at the surface of the water exposed to the air. Experiments were accordingly made in which the surfaces of the water exposed to the air were kept continuously broken.

No. 4.-A tube $1100 \mathrm{~mm}$. long and $50 \mathrm{~mm}$. diameter was filled with nitrogen-free sea-water, and immersed in the water-jacket to a depth of $1025 \mathrm{~mm}$. A glass stirrer of a gridiron shape, $40 \mathrm{~mm}$. broad, was fixed to dip $25 \mathrm{~mm}$. below the surface of the water, and was mechanically rotated for 19 hours. At the end of this time the temperature of the upper layer of the water-column above the water-jacket was $8^{\circ} .3 \mathrm{C}$., and that of the water-jacket $7^{\circ} \cdot 8 \mathrm{C}$. Samples were drawn form the top and bottom layers of the water-column, and the nitrogen determined in each, with the following results:-

$\begin{array}{lc}\text { Top layer. } & \text { Bottom layer. } \\ \mathbf{1 2} 69 & 12.45 \\ \text { At commencement. } & 1.51\end{array}$

No. 5.-A similar experiment was made with distilled water, with results as follows:-

$\begin{array}{lr}13 \cdot 29 & 11 \cdot 02 \\ \text { At commencement. } & 1 \cdot 46\end{array}$

Sea-water saturated at $8^{\circ} .3 \mathrm{C}$. contains 12.91 c.c. $\mathrm{N}_{2}$ per litre. Distilled water saturated at $8^{\circ} 3 \mathrm{C}$. contains 15.92 c.c. $\mathrm{N}_{2}$ per litre. 
In order to provide in these experiments the means of detecting whether or not the mechanical agitation of the surface-layers of the water-columns caused a circulation of the water to the bottom, a large crystal of potassium bichromate was placed at the bottom of the tubes; but in no case was the dissolved bichromate observed to rise above the immediate neighbourhood of the crystal, and become mixed with the water above it.

The results of the last two experiments proved, as was anticipated, that the downward streaming effect takes place so rapidly when the surface of the water exposed to the air is continuously agitated, that long columns of water are completely saturated with atmospherie gases with comparative rapidity.

Experiments were next made in which the surfaces of the water-column were kept broken by means of slow currents of air. It was thought that by their means it would be easy to make comparative observations on the effect of agitating different thicknesses of the surface-layers of two or more columns of water by the same disturbing cause.

No. 6.-Two tubes, each $1980 \mathrm{~mm}$. long and $24 \mathrm{~mm}$. bore, were filled with nitrogen-free sea-water. Each tube was fitted with an indiarubber cork and tine glass inlet and exit tubes of $3 \mathrm{~mm}$. bore, and they were connected in series so that the same current of air could be drawn through the surface-layers of each column of water. The inlet-tube through which the current of air was first drawn dipped $100 \mathrm{~mm}$. below the surface of the first column, and the second inlet-tube dipped $10 \mathrm{~mm}$. below the surface of the second column, of water. The current of air was not previously filtered. It was continued for 25 hours. At conclusion temperature of room was $19^{\circ} .5 \mathrm{C}$, and of the jacket $15^{\circ} \cdot 7 \mathrm{C}$.

Sea-water saturated at $19^{\circ} .50$ C. contains 10.50 c.c. $\mathrm{N}_{2}$ per litre.

\begin{tabular}{|c|c|c|}
\hline $\begin{array}{l}\text { Wepth of Layer } \\
\text { below suriace. }\end{array}$ & 1. & 2. \\
\hline 1 to $100 \mathrm{~mm}$. & $10 \cdot 57$ & $8 \cdot 01$ \\
\hline 1500 to 1600 & $8 \cdot 91$ & 4.08 \\
\hline Before aëration" & $1 \cdot 58$ & $1 \cdot 56$ \\
\hline
\end{tabular}


No. 7.-Similar to the experiment No. 6, with the exception that the inlet-tube dipped $10 \mathrm{~mm}$. below the surface in the first column of water, and $100 \mathrm{~mm}$. in the second column. The current of air was continued for 20 hours. Temperature of room at conclusion was $18^{\circ} \cdot 2 \mathrm{C}$., and of the jacket $14^{\circ} \cdot 9 \mathrm{C}$.

Sea-water at $18^{\circ} \cdot 2$ C. contains $10 \cdot 68$ c.c. $\mathrm{N}_{2}$ per litre.

\begin{tabular}{|c|c|c|}
\hline $\begin{array}{l}\text { Depth of Layer } \\
\text { below surface. }\end{array}$ & 1. & \\
\hline 1 to $100 \mathrm{~mm}$. & $10 \cdot 07$ & $9 \cdot 95$ \\
\hline 1000 to 1100 & - & 605 \\
\hline 1200 to 1300 & $9 \cdot 61$ & - \\
\hline 1700 to 1800 & $6 \cdot 26$ & $2 \cdot 15$ \\
\hline Before aëration . & $1 \cdot 61$ & 1.5 \\
\hline
\end{tabular}

The sea-water employed for the experiments thus far recorded was collected in Dublin Bay. It had been stored in partially full bottles for some weeks previous to use. It contained $19 \cdot 57$ parts chlorine per litre.

From the foregoing results it appears that the rate of aëration, as a consequence of the streaming, was not materially affected by difference of depth of the air-inlet tubes, when two water-columns were aërated in series by the same current of air. The inlet-tubes dipped $100 \mathrm{~mm}$. and $10 \mathrm{~mm}$. below the surfaces in the columns of water 1 and 2 respectively in experiment No. 6 , and vice versa in experiment No. 7 ; and yet both the columns of water which first received the air-currents in the two experiments were found to have dissolved more nitrogen than either of the second columns of water.

It appears, therefore, from these experinients that something was taken from the air by the first water-column in each experiment in addition to the ordinary atmospheric gases, and that very little reached either of the second columns.

The next experiments were arranged with a view to ascertaining whether, by using slower currents of air and fine capillary glass inlet and exit tubes of $0.5 \mathrm{~mm}$. bore, the streaming effect could be completely confined to the first water-column.

No. 8.-Three tubes, each containing sea-water nearly nitrogen-free, were fitted with indiarubber corks and air-inlet and exit tubes, and were connected in series so that the same current of air conld be drawn through the upper layer of each column of water to a depth of $200 \mathrm{~mm}$., one after the other. 
The air-current was a slow one, at the rate of about 1 litre per hour. The aëration was continued for 48 hours and then stopped. Samples of water were then drawn from each tube as before, and stored in glass vessels standing over mercury. The nitrogen determinations are given below. The tube in which the air-current first entered was marked 1, and the one it next entered 2 , and so on. The air was filtered through glass-wool.

Temperature of room $12^{\circ} \cdot 8$ to $10^{\circ} \cdot 0 \mathrm{C}$. Temperature of jacket $8^{\circ} \cdot 6$ to $8^{\mathfrak{3}} \cdot 3 \mathrm{C}$.

Sea-water at $10^{\circ}$ C. contains $12 \cdot 47$ c.c. $\mathrm{N}_{2}$ per litre.

Depth of Layer.

1.

1 to $200 \mathrm{~mm}$. ...... $12 \cdot 24$

800 to $1000, \quad \ldots . .88 \cdot 20$

1600 to $1800, " \ldots . .88 .13$

Before aëration ........ 1.57
2.

$11 \cdot 15$

$2 \cdot 29$

$2 \cdot 18$

$2 \cdot 13$
3.

$11 \cdot 09$

$2 \cdot 55$

$2 \cdot 54$

$2 \cdot 51$

No. 9.-Similar to the experiment No. 8, with the exception that the air-inlet tubes dipped only $50 \mathrm{~mm}$. below the surface. The air-current was filtered through glass-wool.

Temperature of room $13^{\circ} .7$ to $13^{\circ} .5 \mathrm{C}$.

Temperature of jacket $8^{\circ} .4$ to $8^{\circ} .5 \mathrm{C}$.

Sea-water at $13^{\circ} .5$ C. contains $11 \cdot 67$ c.c. $\mathrm{N}_{2}$ per litre.

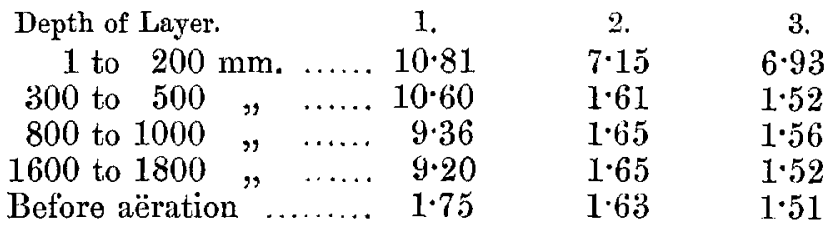

These results show that, when the current of air is sufficiently washed during its passage through the surface-layer of the first column of sea-water, it may be passed through the surface-layers of other columns of sea-water and no streaming effect occurs; although the layer of water through which the air is bubbled soon becomes saturated with atmospheric nitrogen.

It may therefore be concluded that the streaming effect is not due to concentrated solution currents, as suggested by Hüfner, but by something in the air besides its chief gaseous constituents; and that when the something is washed out, the subsequent solution of the gases is not attended by streaming.

The sea-water employed for these experiments was also 
collected in Dublin Bay. It was filtered through glasswool and stored in glass bottles for a week before use. It contained $19 \cdot 45$ grms. chlorine per litre.

Similar experiments were made with distilled water, as there were reasons for anticipating that the cause of the streaming would not be so rapidly washed out by distilled water as by sea-water.

\section{Eatperiments with Distilled Water.}

No. 10.-Similar to experiment No. 8, with the exception that distilled water was used in place of sea-water.

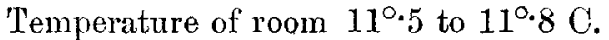

T'emperature of jacket $8^{\circ} .5$ to $9^{\circ} .0 \mathrm{C}$.

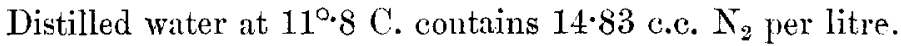
Depth of Layer

below surface.

1.

1 to $200 \mathrm{~mm}$. ...... $14 \cdot 60$

300 to $500, \ldots . . .11 \cdot 62$

800 to $1000 \quad, \quad \ldots . .4 \cdot 48$

1600 to $1800,, \quad \ldots . .354$

Before aëration ........ 155

2.

$12 \cdot 27$

$11 \cdot 10$

$4 \cdot 20$

$3 \cdot 05$

$1 \cdot 73$
3.

$12 \cdot 20$

$11 \cdot 18$

$4 \cdot 48$

$3 \cdot 20$

$1 \cdot 97$

No. 11.-Similar to No. 10, with the exception that the aircurrent was not filtered.

Temperature of room $12^{\circ}$ to $10^{\circ} \mathrm{C}$.

Temperature of jacket $8^{\circ .7}$ to $8^{\circ} .5 \mathrm{C}$.

Distilled water saturated at $10^{\circ} \mathrm{C}$. contains $15 \cdot 37$ c.e. $\mathrm{N}_{2}$ per litre.

Depth of Layer

below surface.

1.

2.

3.

1 to $200 \mathrm{~mm}$. ...... $13 \cdot 81$

300 to 500, ,... $12 \cdot 20$

$12 \cdot 77$

$12 \cdot 64$

800 to $1000 \quad$ "..... $5 \cdot 20$

$11 \cdot 17$

$5 \cdot 17$

11.08

1600 to $1800,, \quad \ldots \ldots .4 \cdot 15$

$4 \cdot 06$

$5 \cdot 14$

Before aëration ........ $1 \cdot 75$

1.55

$4 \cdot 00$

1.51

These experiments confirm the conclusion which was drawn from the results of experiment No.1, viz., that the downward aëration of distilled water by the streaming effect is not so rapid as the aëration of sea-water by the same means.

They also show that the cause of the streaming was not concentrated in the first water-column, as was the case with seawater, but that, on the contrary, it equally affected the tbree water-columns. It may be inferred from this last observation that the streaming being less in distilled water than in sea-water, is due to the something cansing it being more slowly taken out of the air-current by the former than by the latter. 
The following experiment was also made with distilled water, wide bore, $3 \mathrm{~mm}$., inlet and exit tubes being employed. The inlet-tube dipped $25 \mathrm{~mm}$. below the surface of the water :-

No. 12.-A tube $1980 \mathrm{~mm}$. long and $24 \mathrm{~mm}$. bore was filled with nitrogen-free distilled water, and the air-current continued for 12 hours. Temperature of room $15^{\circ} .5 \mathrm{C}$., of jacket $12^{\circ} \cdot 9 \mathrm{C}$.

Depth of Layer.

0 to 200

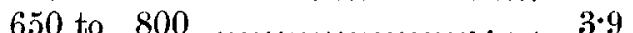

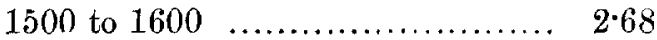

Before aëration ................... 1.51

The question arises, what is the active cause of the streaming? The author does not desire at this stage of his investigation to definitely advance any explanation of the facts observed. One, however, which is suggested by the experiments that have been described, may be pointed out. It is that the streaming is possibly caused by minute dust particles, or by other centres of condensation possibly of an electrical nature, carried by the air-current and being taken up by the water together with the gaseous constituents of the air, and that these bring about in some way a sufficient density of the dissolved or liquefied gases to render it possible for them to be drawn gravitationally downwards through the water.

The fact that the streaming is more marked in sea than in distilled water may be explained by assuming that the sea-water, from the salts which it holds in solution, is able to make more use of the centres of condensation introduced by the air which is bubbled through it. When sea-water and distilled water are separately shaken up with the air, the difference of behaviour of the two waters is, as is well known, very marked, it being easy to obtain a formation of small bubbles of air in sea-water to an extent quite impossible in distilled water.

There can be no question, from the experiments recorded, that if the air be completely washed, the surface of sea-water exposed to it will become saturated with nitrogen, but no streaming effects will take place.

It is equally evident from these experiments, that whatever may subsequently be discovered to be the true cause of the streaming, its effect in large volumes of sea- or river-water under natural conditions must be of great importance, and of such dimensions that the effect of ordinary diffusion may, in comparison, be entirely neglected.

Phil. Mag. S. 6. Vol. 9. No. 51. March 1905. 2 B 